\title{
The Prevalence of Metabolic Syndrome and Factors Associated with Quality of Dialysis among Hemodialysis Patients in Southern Taiwan
}

\author{
Shu-Fen $\mathrm{Tu}^{1}$, Yu-Ching Chou ${ }^{2}$, Chien-An Sun ${ }^{3}$, Shu-Chun $\mathrm{Hsueh}^{4} \&$ Tsan Yang ${ }^{4}$ \\ ${ }^{1}$ Chen Xiangguo joint clinics, Tainan, Taiwan \\ ${ }^{2}$ School of Public Health, National Defense Medical Center, Taipei City, Taiwan \\ ${ }^{3}$ Department of Public Health, College of Medicine, Fu Jen Catholic University, New Taipei City, Taiwan \\ ${ }^{4}$ Department of Health Business Administration, Meiho University, Pingtung, Taiwan \\ Correspondence: Tsan Yang, Department of Health Business Administration, Meiho University, Ping Kuang \\ Road, Neipu, Pingtung, 91202, Taiwan, ROC. Tel: 011-886-8-779-9821 ext 8334. Fax: 011-886-8-778-0673. \\ E-mail: tsan.yang@msa.hinet.net
}

Received: June 18, 2012 Accepted: July 4, 2012 Online Published: July 18, 2012

doi:10.5539/gjhs.v4n5p53 URL: http://dx.doi.org/10.5539/gjhs.v4n5p53

\begin{abstract}
Objectives: The purpose of this study was to evaluate the prevalence of metabolic syndrome (MetS) among hemodialysis patients and factors associated with quality of dialysis.
\end{abstract}

Methods: Data were collected from 377 long-term hemodialysis patients who received hemodialysis treatment from clinics in Tainan and Kaohsiung between November 2009 and February 2010. MetS was defined using criteria set by the adult treatment panel III (ATP-III). But, the cutpoint of waist circumference has been modified to adjust for Asian populations.

The measurement of $\mathrm{Kt} / \mathrm{V}$ was used as an indicator of the quality of dialysis. A below $1.4 \mathrm{Kt} / \mathrm{V}$ was considered poor dialysis quality.

Results: Results showed that the prevalence of MetS among the chronic hemodialysis patients in this sample was $61.0 \%$. Logistic regression results identified that the quality of dialysis in females was better than that in males (odds ratio $(\mathrm{OR})=7.98,95 \%$ confidence interval $(\mathrm{CI}): 2.52-25.31$ ). Better quality dialysis was associated with older age, longer treatment time, and increased blood flow rate ( $\mathrm{OR}=1.49,13.63$, and 1.35, respectively). However, for every one kilogram increase in weight, the quality of dialysis decreased by 13 percents $(\mathrm{OR}=0.87$, 95\% CI: 0.83-0.92).

Conclusions: MetS is common among hemodialysis patients. The prevalence of hypertension, hyperlipidemia, and hyperglycaemia were significantly higher among hemodialysis patients. Quality of dialysis related to gender, age, weight, and the dialysis prescription (treatment time and blood flow rate).

Keywords: hemodialysis, metabolic syndrome, quality of dialysis

\section{Introduction}

Cardiovascular diseases (CVDs) are common among chronic hemodialysis patients, representing the major cause of death: $44 \%$ of the total mortality in dialysis patients (Herzog, Ma, \& Collins, 1998). In a study examining 627,983 long-term dialysis patients from The United States Renal Data System, of the 34,189 hospitalizations because of myocardial infarction between 1977 and 1995, 73\% of the patients died following myocardial infarction, and the mortality rate in five years was nearly $90 \%$ (Herzog et al., 1998). Prevention of CVD among chronic kidney patients is, therefore, crucial. This statistic does not include end-stage renal disease (ESRD) because $30 \%$ of chronic kidney patients have already shown signs of ischaemic heart disease or heart failure before reaching this stage. Therefore, prevention and treatment of CVD are equally important in early chronic kidney disease (CKD) and ESRD (Sarnak, 2003).

Metabolic syndrome (MetS) is an independent predictor of coronary artery diseases, thrombus, and cerebral vascular disease (Najjar, El Gamal, Halabi, \& Leyenson, 2005), and recognized as the major indicator of CVD occurrence and its mortality rate (Trevisan, Liu, Bahsas, \& Menotti, 1998; Isomaa et al., 2001). Epidemiological studies have suggested that the risk of cardiovascular and cerebrovascular disease in patients with MetS was 
$38 \%$ higher than in those without MetS. CVD patients with MetS were also 1.78 times more likely to die than those without MetS (Scuteri, Najjar, Morrell, \& Lakatta, 2005; Gami et al., 2007).

Although the main cause of death in CKD patients is CVD, complications of MetS increase the risk of mortality. In previous studies, the prevalence of MetS was 41.7\% among CKD patients (Lea et al., 2008) and 37.7 to $69.3 \%$ among hemodialysis patients (Young, Lund, Haynatzki, \& Dunlay, 2007; Lucove, Vupputuri, Heiss, North, \& Russell, 2008). In one study in the United States, the prevalence of MetS in uremic patients was $69.3 \%$ (Young et al., 2007). In Taiwan, little is known regarding the prevalence of MetS in hemodialysis patients due to lack of research data. A study conducted in Eastern Taiwan identified that $49.4 \%$ of the sampled dialysis patients also had MetS (Wang, Fang, Shu, Lin, \& Shen, 2009). Existing data from the United States and Eastern Taiwan, therefore, show a high positive correlation between CKD and MetS. The results from a study by Wolfe et al. indicated that the quality of hemodialysis treatment $(\mathrm{Kt} / \mathrm{V})$ is an independent risk factor relating to mortality among hemodialysis patients, and that there was a negative correlation between quality of dialysis and mortality rate (Wolfe, Ashby, Daugirdas, Agodoa, Jones, \& Port, 2000). The factors affecting quality of dialysis include gender, body size [such as weight, body mass index (BMI), and body surface area] and dialysis dose (blood flow rate, treatment time, and the membrane area of the artificial kidney) (Molina et al., 2010). $\mathrm{Kt} / \mathrm{V}$ closely relates to the urea reduction ratio. A higher $\mathrm{Kt} / \mathrm{V}$ value indicates greater hemodialysis efficiency or greater excretion of wastes in blood. The Kidney Disease Outcomes Quality Initiative (K/DOQI) guidelines of the United States recommended a $\mathrm{Kt} / \mathrm{V}$ of 1.2 for patients with three treatments per week. The NKF-DOQI clinical practice guidelines for hemodialysis adequacy, however, recommended a Kt/V of 1.3 (NKF-DOQI, 1997). The study of Held et al. indicated that every 0.1 increase in $\mathrm{Kt} / \mathrm{V}$ can reduce the death risk by $7 \%$, and every $5 \%$ increase in urea reduction ratio (URR) can reduce the death risk by $11 \%$ (Held et al., 1996). Few studies in Taiwan have examined the factors affecting the quality of dialysis. For these reasons, the present study was aiming at evaluating the prevalence of MetS in hemodialysis patients in Southern Taiwan, and also analyzing the factors affecting the quality of dialysis.

\section{Methods}

This was a cross-sectional study, following a research protocol approved by the Institutional Review Board at Meiho University, Pingtung, Taiwan. Participants were long-term hemodialysis patients recruited from the hemodialysis clinics in Tainan and Kaohsiung. These subjects were 18 years old and over, literate, and fluent in Mandarin or Taiwanese. All subjects were diagnosed with stage 5 CKD with over three months of hemodialysis treatment in dialysis clinics. Their costs of dialysis were paid for by the National Health Insurance (NHI), without copayments. Subjects were excluded if they were unconscious, or had mental disorders or metastatic cancer. This study was conducted from November 2009 to February 2010, and 382 hemodialysis patients participated in the survey. Five individuals were excluded because of incomplete information on physical and biochemical blood tests, leaving 377 patients in the current analysis.

In the present study, long-term hemodialysis patients were indicated as patients with chronic renal failure who obtained NHI copayment-waived certification of serious diseases received hemodialysis treatment in hemodialysis clinics for more than three months with a regular three sessions per month, each session lasting for two to five hours. In addition, $\mathrm{Kt} / \mathrm{V}$ is by far the most commonly used marker for dialysis quality, where " $\mathrm{K}$ " represents the dialyzer clearance rate for urea and body water removal $(\mathrm{ml} / \mathrm{min}$ or $\mathrm{L} / \mathrm{h})$, " $\mathrm{t}$ " represents the treatment time ( $\min$ or h), and "V" refers to the urea distribution volume ( $\mathrm{ml}$ or L) (Gotch, 2000; Kooman, van der Sande, \& Leunissen, 2001). The Taiwan Society of Nephrology applies a dialysis quality of 1.3 as the cut-off point during dialysis assessment. Because of the limited number of participants with a dialysis quality of less than 1.3 , the present study adopted a more rigorous dialysis quality standard of 1.4 . A Kt/V of less than 1.4 indicated poorer dialysis quality. Furthermore, the definition of Mets was based on the the criteria set in the Third Report of the National Cholesterol Education Program (NCEP) Expert Panel on Detection, Evaluation, and Treatment of High Blood Cholesterol in Adults (Adult Treatment Panel III, ATP-III) ("Executive Summary of The Third Report of The National Cholesterol Education Program (NCEP) Expert Panel on Detection, Evaluation, And Treatment of High Blood Cholesterol In Adults (Adult Treatment Panel III)," 2001). We utilized previously established modifications for Asian populations, using waist circumference cut-points (Tan, Ma, Wai, Chew, \& Tai, 2004). Any three of the following five criteria were grounds for identifying metabolic syndrome: (1) abdominal obesity: waist circumference (WC) $\geq 90 \mathrm{~cm}$ in men and $\geq 80 \mathrm{~cm}$ in women; (2) raised triglyceride (TG): $\geq 150 \mathrm{mg} / \mathrm{dL}$; (3) reduced high-density lipoprotein cholesterol (HDL-C): HDL-C $<40 \mathrm{mg} / \mathrm{dL}$ in men and $<50 \mathrm{mg} / \mathrm{dL}$ in women; (4) hypertension: blood pressure of at least 130/85 $\mathrm{mm} \mathrm{Hg}$ or taking antihypertensive medication; and (5) raised fasting plasma glucose (FPG) $\geq 110 \mathrm{mg} / \mathrm{dL}$ and/or taking anti-glycemic medication. 


\section{Data Collection}

A self-administered questionnaire was used to collect information on participants' sociodemographic characteristics, medical history, and hemodialysis prescription including dialysis class, dialysis time, flow rate, and membrane area of the artificial kidney. Blood pressure and anthropometric measurements, including height, weight, and WC, were also taken. Height was measured to the nearest $0.1 \mathrm{~cm}$, without shoes, using a stadiometer (Model No.: Hold Cheer BW-120). Weight was measured in light clothing, without shoes, using a beam balance scale, and was recorded to the nearest $0.1 \mathrm{~kg}$. WC was measured to the nearest $0.5 \mathrm{~cm}$ above the iliac crests and below the lowest rib margin at minimal respiration in a standing position. Each participant's blood pressure measurements were obtained using a standardized protocol. Blood pressure was measured by nurses trained to treat hemodialysis patients within 5 to 10 minutes of the start of dialysis treatment. The participant placed the wrist on the bed, palm facing upward, maintaining the arm and heart at the same height. Blood pressure measurements were taken twice using an electronic automatic blood pressure device (model 3M Littmann Classic $2 \mathrm{~S}$. Stethoscope). If the readings varied by more than $10 \mathrm{mmHg}$, an additional measurement was taken. The average of the two closest readings of blood pressures was used in the analysis. Fasting venous blood samples were collected from each subject for a battery of biochemistry analyses. The study subjects had fasted for 12 hours prior to blood collection. Each participant had $12 \mathrm{ml}$ of blood drawn, including one $5-\mathrm{ml}$ sample for biochemical examination, one 3-ml sample for routine blood analysis, and one 2-ml sample for glucose analysis. These blood specimens were retained prior to dialysis treatment, and one further 2-ml of blood was collected for biochemical examination before the end of dialysis treatment. This sample was used to examine the urea nitrogen after dialysis treatment. After entering the examination data into a computer, the $\mathrm{Kt} / \mathrm{V}$ could be calculated to evaluate the quality of dialysis.

\section{Statistical Analysis}

Mean \pm standard deviation (SD), frequency, and percentages were used to describe the characteristics of the study subjects. Independent $t$-test was performed to compare the mean differences in continuous variables between quality of dialysis (good and poor group). Multiple logistic regression was used to estimate the odds ratio for predicted factors affecting dialysis quality. All statistical tests were two-tailed, and values of $\mathrm{p}<0.05$ were considered statistically significant. Data were analyzed using SPSS for Windows, version 17.0 (SPSS Inc., Chicago, IL, USA).

\section{Results}

As shown in Table 1, study subjects had an average age of $64.13 \pm 12.24$ years. Females comprised 203 (53.8\%) participants. Results from anthropometric examinations identified that the average BMI was $22.75 \pm 3.96 \mathrm{~kg} / \mathrm{m}^{2}$, and BMI did not exceed $27 \mathrm{~kg} / \mathrm{m}^{2}$ in most of the study subjects. The average WC was $90.78 \pm 10.19 \mathrm{~cm}$. A total of $272(72.1 \%)$ subjects had abdominal obesity, and $84.4 \%$ of the participants suffered from hypertension. The prevalence rates for hyperglycemia, reduced HDL-C, and hypertriglyceridemia were $53.1 \%, 53.8 \%$, and $36.1 \%$, respectively. The prevalence of MetS was $61.0 \%$. One hundred and seventy-seven (46.9\%) participants received dialysis because of chronic glomerulonephritis, 55 (14.6\%) participants because of chronic interstitial nephritis or hypertensive nephropathy, and $117(31.0 \%)$ participants because of nephropatia diabetes.

Table1. Sociodemographic and clinical characteristics of the study participants

\begin{tabular}{lll}
\hline Variables & Number (\%) & Mean \pm SD \\
\hline Characteristic & & \\
Age & $191(50.7 \%)$ & \\
$<65 \mathrm{yr}$ & $186(49.3 \%)$ & \\
$\geq 65 \mathrm{yr}$ & & \\
Sex & $174(46.2 \%)$ & \\
Male & $203(53.8 \%)$ & \\
Female & & \\
Education level & $77(20.4 \%)$ \\
No & $139(36.9 \%)$ \\
Primary school & $70(18.6 \%)$ \\
Junior high school & \\
\hline
\end{tabular}




\begin{tabular}{|c|c|c|}
\hline High school & $71(18.8 \%)$ & \\
\hline Academy & $11(2.9 \%)$ & \\
\hline College & $9(2.4 \%)$ & \\
\hline \multicolumn{3}{|l|}{ Job } \\
\hline Yes & $62(16.4 \%)$ & \\
\hline No & $315(83.6 \%)$ & \\
\hline \multicolumn{3}{|l|}{ Metablic syndrome components } \\
\hline Height $(\mathrm{cm})$ & & $159.12 \pm 9.24$ \\
\hline Weight(kg) & & $57.66 \pm 11.20$ \\
\hline Body mass index $\left(\mathrm{kg} / \mathrm{m}^{2}\right)$ & & $22.75 \pm 3.96$ \\
\hline $\mathrm{BMI}<27$ & $335(88.9 \%)$ & \\
\hline $\mathrm{BMI} \geq 27$ & $42(11.1 \%)$ & \\
\hline Waist circumference(cm) & & $90.78 \pm 10.19$ \\
\hline Normal & $105(27.9 \%)$ & \\
\hline Abnormal $^{\text {a }}$ & $272(72.1 \%)$ & \\
\hline Hypertension $(\mathrm{mmHg})^{\mathrm{b}}$ & $318(84.4 \%)$ & \\
\hline Hyperglycemia(mg/dL) $)^{c}$ & $200(53.1 \%)$ & \\
\hline Low HDL-C(mg/dL) ${ }^{\mathrm{d}}$ & $203(53.8 \%)$ & \\
\hline Hypertriglyceridemia $^{\mathrm{e}}$ & $136(36.1 \%)$ & \\
\hline \multicolumn{3}{|l|}{ Number of metabolic syndrome indicators } \\
\hline 0 & $2(0.5 \%)$ & \\
\hline 1 & $46(16.2 \%)$ & \\
\hline 2 & $99(26.3 \%)$ & \\
\hline 3 & $91(24.1 \%)$ & \\
\hline 4 & $83(22.0 \%)$ & \\
\hline 5 & $56(14.9 \%)$ & \\
\hline \multicolumn{3}{|l|}{ Metabolic syndrome } \\
\hline Not present & $147(39.0 \%)$ & \\
\hline Present $^{\mathrm{f}}$ & $230(61.0 \%)$ & \\
\hline \multicolumn{3}{|l|}{$\underline{\text { Reason of dialysis }}$} \\
\hline Cronic glomerulonephritis & $177(46.9 \%)$ & \\
\hline Cronic interstitial nephritis or hypertensive nephropathy & $55(14.6 \%)$ & \\
\hline Nphropatia diabetic & $117(31.0 \%)$ & \\
\hline Other & $28(7.4 \%)$ & \\
\hline \multicolumn{3}{|l|}{ Dalysis treatment } \\
\hline Dialysis duration(yrs) & & $5.71 \pm 3.99$ \\
\hline \multicolumn{3}{|l|}{ Fstula type of hemodialysis } \\
\hline Atologous & $313(83.0 \%)$ & \\
\hline Atificial & $64(17.0 \%)$ & \\
\hline Dialysis treatment time $(\mathrm{h})$ & & $3.99 \pm 0.21$ \\
\hline Area of artificial kidney $\left(\mathrm{m}^{2}\right)$ & & $1.83 \pm 0.24$ \\
\hline Blood flow rate(cc/min) & & $284.06 \pm 39.85$ \\
\hline
\end{tabular}

${ }^{a}$ Male: $\geq 90 \mathrm{~cm}$; female: $\geq 80 \mathrm{~cm}$. ${ }^{\mathrm{b}} \geq 130 / 85 \mathrm{mmHg}$ or taking antihypertensive medication. ${ }^{\mathrm{c}} \geq 110 \mathrm{mg} / \mathrm{dL}$ or taking medication for lowering blood glucose. ${ }^{\mathrm{d}} \mathrm{HDL}-\mathrm{C}$ : high-density lipoprotein cholesterol: Male: $<40 \mathrm{mg} / \mathrm{dL}$; female $<50 \mathrm{mg} / \mathrm{dL}$. ${ }^{\mathrm{e}} \geq 150 \mathrm{mg} / \mathrm{dL}$. ${ }_{\mathrm{f}}^{\mathrm{f}}$ Metabolic syndrome definition of NCEP ATP III with modification for Asian populations 
The average duration of dialysis in the study subjects was $5.71 \pm 3.99$ years (range: less than 1 to 22 years). 313 $(83.0 \%)$ subjects received autologous fistula for hemodialysis, and $64(17.0 \%)$ subjects received artificial fistula. Each dialysis treatment session lasted an average of $3.99 \pm 0.21$ hours; more than four hours in $354(93.9 \%)$ subjects and less than four hours in $23(6.1 \%)$ subjects. The smallest membrane area of the artificial kidney was $1.3 \mathrm{~m}^{2}$, the largest area was $2.5 \mathrm{~m}^{2}$, and the average was $1.83 \pm 0.24 \mathrm{~m}^{2}$. The lowest flow rate of each dialysis was $170 \mathrm{~mL} / \mathrm{min}$, the highest was $350 \mathrm{~mL} / \mathrm{min}$, and the average was $284.1 \pm 39.9 \mathrm{~mL} / \mathrm{min}$.

Table 2 displays the laboratory analyses data of hemodialysis patients. FPG, HDL-C, and uric acid levels had the highest percentages of abnormal values; $48.3 \%, 53.8 \%$, and $58.1 \%$, respectively.

Table 2. Laboratory analyses data of hemodialysis patients

\begin{tabular}{|c|c|c|c|c|c|}
\hline Variables & Mean & SD & $\begin{array}{l}\text { Normal } \\
\mathrm{n}(\%)\end{array}$ & $\begin{array}{l}\text { Abnormal } \\
\mathrm{n}(\%)\end{array}$ & Definition of abnormal \\
\hline Pre-dialysis BUN(mg/dL) & 65.37 & 15.46 & & & \\
\hline post-dialysis BUN(mg/dL) & 17.39 & 11.82 & & & \\
\hline $\mathrm{Ca}(\mathrm{mg} / \mathrm{dL})$ & 9.73 & 0.76 & $279(74.0 \%)$ & $98(26.0 \%)$ & $>10.1$ \\
\hline $\mathrm{P}(\mathrm{mg} / \mathrm{dL})$ & 5.04 & 1.32 & $255(67.6 \%)$ & $122(32.4 \%)$ & $>5.5$ \\
\hline $\mathrm{K}(\mathrm{mmol} / \mathrm{L})$ & 4.85 & 0.68 & $246(65.3 \%)$ & $131(34.7 \%)$ & $>5$ \\
\hline Hemoglobin(g/dL) & 10.90 & 1.17 & & & \\
\hline Hemotocrit(\%) & 33.25 & 3.78 & $315(83.6 \%)$ & $62(16.4 \%)$ & $<30$ \\
\hline Fasting plasma glucose $(\mathrm{mg} / \mathrm{dL})$ & 126.03 & 57.69 & $195(51.7 \%)$ & $182(48.3 \%)$ & $\geq 110$ \\
\hline $\mathrm{HDL}-\mathrm{C}(\mathrm{mg} / \mathrm{dL})$ & 46.07 & 13.58 & $174(46.2 \%)$ & $203(53.8 \%)$ & male $<40$ or female $<50$ \\
\hline Triglyceride $(\mathrm{mg} / \mathrm{dL})$ & 143.67 & 82.72 & $241(63.9 \%)$ & $136(36.1 \%)$ & $\geq 150$ \\
\hline Total cholesterol(mg/dL) & 177.96 & 36.24 & $277(73.5 \%)$ & $100(26.5 \%)$ & $>200$ \\
\hline $\operatorname{Albumin}(\mathrm{g} / \mathrm{dL})$ & 3.93 & 0.27 & $249(66.0 \%)$ & $128(34.0 \%)$ & $\leq 3.8$ \\
\hline Alk-P(U/L) & 88.94 & 51.42 & $330(87.5 \%)$ & $47(12.5 \%)$ & $>140$ \\
\hline Uric $\operatorname{acid}(\mathrm{mg} / \mathrm{dL})$ & 7.45 & 1.38 & $158(41.9 \%)$ & $219(58.1 \%)$ & $>7$ \\
\hline GOT(U/L) & 24.92 & 29.57 & $343(91.0 \%)$ & $34(9.0 \%)$ & $>38$ \\
\hline GPT(U/L) & 23.92 & 37.72 & $339(89.9 \%)$ & $38(10.1 \%)$ & $>40$ \\
\hline
\end{tabular}

The present study used a dialysis quality (Kt/V) of 1.4 as the cut-off point to divide the study subjects into two groups. Non-significant associations were found between metabolic syndrome-related indicators and hemodialysis quality (see table 3). Table 4 shows the differences between the groups on characteristics and laboratory analyses data. Patients with higher dialysis quality tended to be older and had shorter duration dialysis treatment time than patients with poor dialysis quality ( $<<0.001$ and $p=0.017$, respectively). Height, weight, WC, and BMI were significantly higher in the hemodialysis patients with poor dialysis quality than those with higher dialysis quality $(\mathrm{p}<0.001)$. The hemodialysis patients with poor dialysis quality showed significantly higher average values for membrane area of the artificial kidney, blood flow rate, and systolic and diastolic blood pressures compared to patients with higher dialysis quality $(\mathrm{p}<0.001, \mathrm{p}=0.001, \mathrm{p}=0.011$, and $\mathrm{p}<0.001$, respectively). Results from laboratory examinations indicated that the blood urea nitrogen and albumin levels after dialysis were significantly higher in hemodialysis patients with poor dialysis quality than in patients with higher dialysis quality $(\mathrm{p}<0.001$ and $\mathrm{p}=0.018$, respectively). HDL-C was lower in hemodialysis patients with poor dialysis quality than in patients with higher dialysis quality $(\mathrm{p}=0.004)$.

Table 3. The differences of dialysis quality in the metabolic syndrome and and its components

\begin{tabular}{llcl}
\hline \multirow{2}{*}{ Variables } & \multicolumn{2}{l}{ Quality of dialysis (Daugirdas } & \multicolumn{2}{c}{ Quality of dialysis (Daugirdas } & \multirow{2}{*}{$P^{*}$ value } \\
\hline KT/V) $\leq 1.4 . \quad \mathrm{n}=65,(5.3 \%)$ & $\mathrm{KT} / \mathrm{V})>1.4 . \quad \mathrm{n}=312(94.7 \%)$ & .350 \\
Netabolic syndrome & & & $125(85.0 \%)$
\end{tabular}


Present $^{\mathrm{a}}$

Waist circumference $(\mathrm{cm})$

Normal

Abdominal obesity ${ }^{\mathrm{b}}$

Triglyceride $(\mathrm{mg} / \mathrm{dL})$

Normal

Hypertriglyceridemia $^{c}$

HDL-C(mg/dL)

Normal

Low HDL-C ${ }^{\mathrm{d}}$

Blood Pressure $(\mathrm{mmHg})$

Normal

Hypertension $^{\mathrm{e}}$

Fasting plasma glucose (mg/dL)

Normal

Hyperglycemia $^{\mathrm{f}}$
43(18.7\%)

$187(81.3 \%)$

$18(17.1 \%)$

47(17.3\%)

$38(15.8 \%)$

$27(19.9 \%)$

26(14.9\%)

$39(19.2 \%)$

$6(10.2 \%)$

$59(18.6 \%)$

$33(18.6 \%)$

$32(16.0 \%)$
$87(82.9 \%)$

$225(82.7 \%)$

.975

203(84.2\%)

$109(80.1 \%)$

$148(85.1 \%)$

164(80.8\%)

$53(89.8 \%)$

$259(81.4 \%)$

.498

$144(81.4 \%)$

$168(84.0 \%)$

${ }^{\mathrm{a}}$ Metabolic syndrome definition of NCEP ATP III with modification for Asian populations. ${ }^{\mathrm{b}}$ Male: $\geq 90 \mathrm{~cm}$; female: $\geq 80 \mathrm{~cm}$. ${ }^{\mathrm{c}} \geq 150 \mathrm{mg} / \mathrm{dL} .{ }^{\mathrm{d}}$ Male: $<40 \mathrm{mg} / \mathrm{dL}$; female $<50 \mathrm{mg} / \mathrm{dL} .{ }^{\mathrm{e}} \geq 130 / 85 \mathrm{mmHg}$ or taking antihypertensive medication. ${ }^{\mathrm{f}} \geq 110 \mathrm{mg} / \mathrm{dL}$ or taking medication to lower blood glucose.

${ }^{*}$ The Chi-square (two-tailed) test was used to compare the variables, with a significance level of $\alpha=.05$

Table 4. The differences of dialysis quality in the subjects' demographic characteristics and laboratory analyses data

\begin{tabular}{|c|c|c|c|}
\hline Variables & $\begin{array}{l}\text { Quality of dialysis (Daugirdas } \\
\text { KT/V) } \leq 1.4 \\
\mathrm{n}=65,(5.3 \%)\end{array}$ & $\begin{array}{l}\text { Quality of dialysis (Daugirdas } \\
\text { KT/V) }>1.4 \\
n=312(94.7 \%)\end{array}$ & $\mathrm{P}^{*}$ value \\
\hline Age(yrs) & $58.31 \pm 12.57$ & $65.34 \pm 11.83$ & $<.001$ \\
\hline Height $(\mathrm{cm})$ & $166.60 \pm 7.35$ & $157.76 \pm 8.04$ & $<.001$ \\
\hline Weight(kg) & $69.20 \pm 11.62$ & $55.26 \pm 9.50$ & $<.001$ \\
\hline $\mathrm{WC}(\mathrm{cm})$ & $96.16 \pm 10.63$ & $89.66 \pm 9.74$ & $<.001$ \\
\hline $\operatorname{BMI}\left(\mathrm{kg} / \mathrm{m}^{2}\right)$ & $24.94 \pm 3.90$ & $22.29 \pm 3.82$ & $<.001$ \\
\hline Dialysis duration(yrs) & $4.75 \pm 3.35$ & $5.91 \pm 4.10$ & .017 \\
\hline Dialysis treatment time $(\mathrm{hr})$ & $4.01 \pm 0.35$ & $3.99 \pm 0.17$ & .697 \\
\hline Area of artificial kidney $\left(\mathrm{m}^{2}\right)$ & $2.00 \pm 0.24$ & $1.79 \pm 0.23$ & $<.001$ \\
\hline Blood flow rate(cc/min) & $297.85 \pm 30.49$ & $282.45 \pm 35.65$ & .001 \\
\hline Systolic blood pressure $(\mathrm{mmHg})$ & $150.57 \pm 24.71$ & $142.69 \pm 22.33$ & .011 \\
\hline Diastolic blood pressure $(\mathrm{mmHg})$ & $83.02 \pm 12.96$ & $77.01 \pm 10.48$ & $<.001$ \\
\hline $\mathrm{Ca}(\mathrm{mg} / \mathrm{dL})$ & $9.60 \pm 0.79$ & $9.75 \pm 0.75$ & .154 \\
\hline $\mathrm{P}(\mathrm{mg} / \mathrm{dL})$ & $5.31 \pm 1.51$ & $4.99 \pm 1.28$ & .071 \\
\hline $\mathrm{Ca} \times \mathrm{P}(\mathrm{mg} / \mathrm{dL})^{2}$ & $51.17 \pm 15.45$ & $48.89 \pm 14.16$ & .245 \\
\hline $\mathrm{K}$ & $4.78 \pm 0.67$ & $4.86 \pm 0.68$ & .367 \\
\hline Pre-dialysis BUN(mg/dL) & $68.73 \pm 19.92$ & $64.67 \pm 14.30$ & .122 \\
\hline post-dialysis BUN(mg/dL) & $23.93 \pm 9.22$ & $16.03 \pm 11.86$ & $<.001$ \\
\hline Fasting plasma glucose (mg/dL) & $123.82 \pm 62.01$ & $126.49 \pm 56.83$ & .734 \\
\hline Hemotocrit(\%) & $33.65 \pm 4.34$ & $33.17 \pm 3.65$ & .356 \\
\hline $\mathrm{HDL}-\mathrm{C}(\mathrm{mg} / \mathrm{dL})$ & $41.65 \pm 11.76$ & $46.99 \pm 13.77$ & .004 \\
\hline Triglyceride $(\mathrm{mg} / \mathrm{dL})$ & $152.09 \pm 98.49$ & $141.91 \pm 79.11$ & .367 \\
\hline
\end{tabular}


Total cholesterol(mg/dL)

Uric acid(mg/dL)

$\operatorname{Albumin}(\mathrm{g} / \mathrm{dL})$

GOT(U/L)

GPT(U/L)

$173.17 \pm 32.01$
$7.60 \pm 1.39$
$4.02 \pm 0.32$
$20.11 \pm 9.82$
$19.92 \pm 13.32$

$\begin{array}{ll}178.96 \pm 37.03 & .242 \\ 7.42 \pm 1.38 & .334 \\ 3.91 \pm 0.25 & .018 \\ 25.93 \pm 32.11 & .149 \\ 24.75 \pm 40.98 & .349\end{array}$

*Independent t-test was used to compare the variables and adopted two-tailed test, the significant level $\alpha=0.05$

Multiple logistic regression analysis was used to examine the predictive factors for quality of dialysis. Potential factors for the model included age, gender, height, weight, dialysis treatment time, area of artificial kidney, blood flow rate, systolic and diastolic blood pressures, uric acid, and blood urea nitrogen before dialysis (Table 5). Results showed that, for every ten years' increase in age, there was a 1.49 times higher probability of receiving higher dialysis quality $(\mathrm{Kt} / \mathrm{V}>1.4)$ than poor dialysis quality $(\mathrm{Kt} / \mathrm{V} \leq 1.4)(95 \%$ CI: $1.06-2.01)$. The quality of dialysis was higher in females than in males ( $\mathrm{OR}=7.98,95 \% \mathrm{CI}: 2.52-25.31)$. Each $1 \mathrm{~kg}$ increase in body weight, the quality of dialysis decreased by 13 percents $(\mathrm{OR}=0.87,95 \%$ CI: $0.83-0.92)$.

Table 5. Multiple logistic regression analysis of the predictors for quality of dialysis

\begin{tabular}{llll}
\hline Variables & $\beta$ & OR(95\%CI) & p-vale $^{*}$ \\
\hline Age (yrs) & 0.40 & $1.49(1.06-2.01)$ & .021 \\
Gender $^{\mathrm{a}}$ & 2.08 & $7.98(2.52-25.31)$ & $<.001$ \\
Height(cm) & -0.01 & $0.99(0.93-1.06)$ & .853 \\
Weight(kg) & -0.13 & $0.87(0.83-0.92)$ & $<.001$ \\
Dialysis treatment time(hr) & 2.61 & $13.63(2.51-74.01)$ & .002 \\
Area of artificial kidney(m $\left.{ }^{2}\right)$ & -1.20 & $0.30(0.04-2.12)$ & .227 \\
Blood flow rate(cc/min) & 0.30 & $1.35(1.04-1.74)$ & .023 \\
Systolic blood pressure(mmHg) & 0.16 & $1.17(0.95-1.45)$ & .148 \\
Diastolic blood pressure(mmHg) & -0.38 & $0.68(0.43-1.01)$ & .094 \\
Uric acid(mg/dL) & b & $2.24(0.96-5.23)$ & .063 \\
Pre-dialysis BUN(mg/dL) & 0.81 & $0.98(0.96-1.01)$ & .292 \\
Constant & -0.02 & & .624
\end{tabular}

Note: Dependent variable: quality of dialysis $(\mathrm{Kt} / \mathrm{V})$, using the $\leq 1.4$ group as the reference group; ${ }^{*} \mathrm{OR}(95 \% \mathrm{CI})=\mathrm{odds}$ ratio (95\% confidence interval); ${ }^{\mathrm{a}} \mathrm{Male}$ as the reference group; ${ }^{\mathrm{b}} \mathrm{Using}$ the uric acid $\leq 7$ as the reference group

Every one hour increase in dialysis treatment time increased the probability of receiving higher dialysis quality than poor dialysis quality by 13.63 times (95\% CI: 2.51-74.01). Each $20 \mathrm{ml} / \mathrm{min}$ increase in blood flow rate contributed to a higher dialysis quality $(\mathrm{OR}=1.35,95 \% \mathrm{CI}$ : $1.02-1.32)$. The other variables did not significantly influence the quality of dialysis.

\section{Discussion}

In the general population, the prevalence of MetS is less than 30\%. For instance, prior research has identified prevalence rates of $20.4 \%$ in Latin America (Escobedo et al., 2009), 26.9\% in Japan (Miyatake, Kawasaki, Nishikawa, Takenami, \& Numata, 2006), and 24.8\% in South Korea (Kwon et al., 2005). In the event of diseases, the prevalence of MetS is considerably higher. For example, in previous studies the prevalence of mental disease with MetS was 34.2\% (Kim et al., 2010), and the prevalence of heart disease with MetS was 53.2\% (Yoo, Jeong, Park, Kang, \& Ahn, 2009). The present study's subjects consisted of patients undergoing long-term hemodialysis treatment in hemodialysis clinics in Southern Taiwan. A total of 377 effective samples were used, and the prevalence of MetS was $61.0 \%$. This figure was considerably higher than the prevalence of MetS in a hemodialysis group in Eastern Taiwan (49.4\%) (Wang et al., 2009). The differences may have resulted from the different criteria applied for the diagnosis of MetS; Wang et al. used the NCEP-ATP III criteria, whereas the present study applied the criteria of the NCEP-ATP III. Waist circumference was modifed for Asian populations. The differences occurred in the criteria for WC (NCEP-ATP III criteria specified a WC of $\geq 102 \mathrm{~cm}$ in males and 
$\geq 88 \mathrm{~cm}$ in females) and the sample size (the study by Wang et al. had 146 subjects). Wang et al. recruited subjects from a single hemodialysis center, whereas the present study recruited subjects from four different hemodialysis clinics, and therefore, is a closer representation of the actual MetS situation. These results demonstrated that the prevalence of MetS is higher in the presence of complications of other diseases than without other disorders.

In the present study, the prevalence of hypertension, abdominal obesity, hyperglycemia, reduced HDL-C, and hypertriglyceridemia was $84.4 \%, 72.1 \%, 53.1 \%, 58.3 \%$, and $36.1 \%$, respectively. Other related studies provided similar results for the prevalence of hypertension (Young et al., 2007; Wang et al., 2009). Hypertension arises because of renal function insufficiency. The renal drainage ability of the hemodialysis patient decreases, and therefore, the body cannot immediately discharge excess water. The patient requires dialysis treatment to discharge the water through a dialyzer. Current dialysis treatment takes three sessions per week, each session lasting approximately 3.5 to 5 hours. Before receiving dialysis, the excess water and stagnation of sodium increase the burden on the heart, the activity of the peripheral nervous system, and total peripheral vascular resistance, leading to symptoms of hypertension (Young et al., 2007; Wang et al., 2009).

In the present study, the prevalence of abdominal obesity was $72.1 \%$, which was higher than the other studies conducted by Wang, Young, and their colleagues (Young et al., 2007; Wang et al., 2009). The research of Sandeep et al. (2010) identified that abdominal obesity relates to insulin resistance, cardiovascular risk factors, and MetS. A study also suggested that obesity relates to comorbidity, including MetS and CVD (Mahjoub, Gamoudi, Jamoussi, Gaigi, \& Blouza-Chabchoub, 2010). Cordeiro et al. (2010) conducted a study on 173 hemodialysis patients, aged 51 to 74, identifying that abdominal obesity increased the risk of death and worsens prognoses. According to the research of Young et al. (2007), individuals with MetS first became overweight or develop obesity, and then risk factors of MetS, specifically abdominal obesity, usually follow. CKD patients should carefully monitor for adverse effects associated with excess weight and obesity because these disorders could directly cause and develop into end-stage renal diseases and sudden death because of diabetes, hypertension, and CVD (Ting, Nair, Ching, Taheri, \& Dasgupta, 2009).

The present study adopted multiple logistic regression analysis to examine the factors influencing the quality of dialysis. Results showed that, when adjusting for potential confounding factors, every increase of 10 years in age resulted in a 1.49 times $(95 \% \mathrm{CI}: 1.06-2.01)$ increased probability of higher dialysis quality $(\mathrm{Kt} / \mathrm{V}>1.4)$ than poor dialysis quality $(\mathrm{Kt} / \mathrm{V} \leq 1.4)$. This indicated that older patients receive higher dialysis quality. Valdes et al. also conducted a study on hemodialysis patients, revealing that patients aged older than 65 years had higher Kt/V than patients aged 65 years old and younger (Valdés, García-Mendoza, Rebollo, T. Ortega, \& F. Ortega, 2006). The dyliasis quality was 7.98 times higher in females than in males $(\mathrm{p}<0.001)$. This result was similar to that of a previous study conducted by Kutner et al. (2005) in which, irrespective of race, quality of dialysis was higher in females than in males. Some studies observed that increasing dialysis treatment time (Termorshuizen et al., 2003), blood flow rate (Borzou, et al., 2009), and area of the artificial kidney led to increases in Kt/V (Molina et al., 2010). In the present study, increasing dialysis treatment time and blood flow rate was also postively correlated with $\mathrm{Kt} / \mathrm{V}$. Previous studies have defined $\mathrm{Kt} / \mathrm{V}$ as the dialysis dose given, where $\mathrm{K}$ refers to the rate of removal of body urea and water by the dialyzer $(\mathrm{ml} / \mathrm{min}$ or $\mathrm{L} / \mathrm{h}), \mathrm{t}$ refers to the treatment time $(\mathrm{min}$ or $\mathrm{h}$ ), and $\mathrm{V}$ represents the urea distribution volume ( $\mathrm{ml}$ or L) (Mahjoub et al., 2010; Miyatake et al., 2006). The urea distribution volume ( $\mathrm{V}=$ weight multiplied by 0.58 ) is positively proportional to the weight and, under constant $\mathrm{K}$ and $\mathrm{t}$, increasing $\mathrm{V}$ causes a reduction in $\mathrm{Kt} / \mathrm{V}$. Therefore, after controlling for these predictive factors for quality of dialysis, increasing weight negatively correlates with Kt/V. In 1999, Beige et al. suggested that BMI negatively affects Kt/V (Beige, Sharma, Distler, Offermann, \& Preuschof, 1999). Weight and BMI positively correlate, and therefore, a heavier weight is related to a greater BMI value. Hence, results from the present study indirectly demonstrated the negative correlation between weight and dialysis quality.

One limitation of this study was the purposive sampling of subjects from Tainan and Kaohsiung hemodialysis clinics; therefore, results could not completely avoid selection bias. Although inferring nationwide hemodialysis trends from the study findings is impossible, the large study population enables the interpretation of the regional quality of dialysis from the results.

In conclusion, the present study identified a prevalence of MetS of $61.0 \%$ in hemodialysis patients. The majority of hemodialysis patients have a preexisting MetS condition. The dialysis quality positively correlated with dialysis prescription (treatment time and blood flow rate), and negatively correlated with weight. Therefore, incorporating strategies for MetS prevention with dialysis prescription can reduce the incidence of hemodialysis and improve dialysis quality. Preventing MetS and its risk factors, accompanied by dialysis dose adjustment, should provide an effective means of reducing the prevalence of dialysis and improve its quality. 


\section{Reference}

Beige, J., Sharma, A. M., Distler, A., Offermann, G., \& Preuschof, L. (1999). Monitoring dialysis efficacy by comparing delivered and predicted Kt/V. Nephrol Dial Transplant, 14(3), 683-687. http://dx.doi.org/10.1093/ndt/14.3.683

Borzou, S. R., Gholyaf, M., Zandiha, M., Amini, R., Goodarzi, M. T., \& Torkaman, B. (2009). The effect of increasing blood flow rate on dialysis adequacy in hemodialysis patients. Saudi J Kidney Dis Transpl, 20(4), 639-642.

Cordeiro, A. C., Qureshi, A. R., Stenvinkel, P., Heimburger, O., Axelsson, J., Barany, P., ... Carrerol, J. J. (2010). Abdominal fat deposition is associated with increased inflammation, protein-energy wasting and worse outcome in patients undergoing haemodialysis. Nephrol Dial Transplant, 25(2), 562-568. http://dx.doi.org/10.1093/ndt/gfp492

Escobedo, J., Schargrodsky, H., Champagne, B., Silva, H., Boissonnet, C. P., Vinueza, R., ... Wilson, E. (2009). Prevalence of the metabolic syndrome in Latin America and its association with sub-clinical carotid atherosclerosis: the CARMELA cross sectional study. Cardiovasc Diabetol, 8, 52. http://dx.doi.org/10.1186/1475-2840-8-52

Executive Summary of The Third Report of The National Cholesterol Education Program (NCEP) Expert Panel on Detection, Evaluation, And Treatment of High Blood Cholesterol In Adults (Adult Treatment Panel III). (2001). JAMA, 285(19), 2486-2497. http://dx.doi.org/10.1001/jama.285.19.2486

Gami, A. S., Witt, B. J., Howard, D. E., Erwin, P. J., Gami, L. A., Somers, V. K., ... Montori, V. M. (2007). Metabolic syndrome and risk of incident cardiovascular events and death: a systematic review and meta-analysis of longitudinal studies. J Am Coll Cardiol, 49(4), 403-414. http://dx.doi.org/10.1016/j.jacc.2006.09.032

Gotch, F. A. (2000). Kt/V is the best dialysis dose parameter. Blood Purif, 18(4), 276-285. http://dx.doi.org/10.1159/000014449

Held, P. J., Port, F. K., Wolfe, R. A., Stannard, D. C., Carroll, C. E., Daugirdas, J. T., ... Hakim, R. M. (1996). The dose of hemodialysis and patient mortality. Kidney Int, 50(2), 550-556. http://dx.doi.org/10.1038/ki.1996.348

Herzog, C. A., Ma, J. Z., \& Collins, A. J. (1998). Poor long-term survival after acute myocardial infarction among patients on long-term dialysis. $N$ Engl $J$ Med, 339(12), 799-805. http://dx.doi.org/10.1056/NEJM199809173391203

Isomaa, B., Almgren, P., Tuomi, T., Forsen, B., Lahti, K., Nissen, M., ... Groop, L. (2001). Cardiovascular morbidity and mortality associated with the metabolic syndrome. Diabetes Care, 24(4), 683-689. http://dx.doi.org/10.2337/diacare.24.4.683

Kim, S. H., Kim, K., Kwak, M. H., Kim, H. J., Kim, H. S., \& Han, K. H. (2010). The contribution of abdominal obesity and dyslipidemia to metabolic syndrome in psychiatric patients. Korean J Intern Med, 25(2), 168-173. http://dx.doi.org/10.3904/kjim.2010.25.2.168

Kooman, J. P., van der Sande, F. M., \& Leunissen, K. M. (2001). Kt/V: finding the tree within the woods. Nephrol Dial Transplant, 16(9), 1749-1752. http://dx.doi.org/10.1093/ndt/16.9.1749

Kutner, N. G., Zhang, R., \& Brogan, D. (2005). Race, gender, and incident dialysis patients' reported health status and quality of life. J Am Soc Nephrol, 16(5), 1440-1448. http://dx.doi.org/10.1681/ASN.2004080639

Kwon, H. S., Park, Y. M., Lee, H. J., Lee, J. H., Choi, Y. H., Ko, S. H., ... Son, H. Y. (2005). Prevalence and clinical characteristics of the metabolic syndrome in middle-aged Korean adults. Korean J Intern Med, 20(4), 310-316. http://dx.doi.org/10.3904/kjim.2005.20.4.310

Lea, J., Cheek, D., Thornley-Brown, D., Appel, L., Agodoa, L., Contreras, G., ... McClellan, W. (2008). Metabolic syndrome, proteinuria, and the risk of progressive CKD in hypertensive African Americans. Am J Kidney Dis, 51(5), 732-740. http://dx.doi.org/10.1053/j.ajkd.2008.01.013

Lucove, J., Vupputuri, S., Heiss, G., North, K., \& Russell, M. (2008). Metabolic syndrome and the development of CKD in American Indians: the Strong Heart Study. Am J Kidney Dis, 51(1), 21-28. http://dx.doi.org/10.1053/j.ajkd.2007.09.014

Mahjoub, F., Gamoudi, A., Jamoussi, H., Gaigi, S., \& Blouza-Chabchoub, S. (2010). Metabolic profile of tunisian obese adult. Tunis Med, 88(6), 394-398. 
Miyatake, N., Kawasaki, Y., Nishikawa, H., Takenami, S., \& Numata, T. (2006). Prevalence of metabolic syndrome in Okayama prefecture, Japan. Intern Med, 45(2), 107-108. http://dx.doi.org/10.2169/internalmedicine.45.1509

Molina Nunez, M., Roca Merono, S., de Alarcon Jimenez, R. M., Garcia Hernandez, M. A., Jimeno Grino, C., Alvarez Fernandez, G. M., ... Silva, P. (2010). Kt calculation as a quality indicator of haemodialysis adequacy. Nefrologia, 30(3), 331-336.

Najjar, N., El Gamal, A., Halabi, S., \& Leyenson, V. A. (2005). 38-year-old man with HIV infection and subacute onset of cough and dyspnea. Chest, 6, 4008-4012. http://dx.doi.org/10.1378/chest.128.6.4008

NKF-DOQI clinical practice guidelines for hemodialysis adequacy. National Kidney Foundation. (1997). Am J Kidney Dis, 30(3 Suppl 2), S15-66.

Sandeep, S., Gokulakrishnan, K., Velmurugan, K., Deepa, M., \& Mohan, V. (2010). Visceral \& subcutaneous abdominal fat in relation to insulin resistance \& metabolic syndrome in non-diabetic south Indians. Indian $J$ Med Res, 131, 629-635.

Sarnak, M. J. (2003). Cardiovascular complications in chronic kidney disease. Am J Kidney Dis, 41(5 Suppl), 11-17. http://dx.doi.org/10.1016/S0272-6386(03)00372-X

Scuteri, A., Najjar, S. S., Morrell, C. H., \& Lakatta, E. G. (2005). The metabolic syndrome in older individuals: prevalence and prediction of cardiovascular events: the Cardiovascular Health Study. Diabetes Care, 28(4), 882-887. http://dx.doi.org/10.2337/diacare.28.4.882

Tan, C. E., Ma, S., Wai, D., Chew, S. K., \& Tai, E. S. (2004). Can we apply the National Cholesterol Education Program Adult Treatment Panel definition of the metabolic syndrome to Asians? Diabetes Care, 27(5), 1182-1186. http://dx.doi.org/10.2337/diacare.27.5.1182

Termorshuizen, F., Korevaar, J. C., Dekker, F. W., Jager, K. J., van Manen, J. G., Boeschoten, E. W., ... Krediet, R. T. (2003). Time trends in initiation and dose of dialysis in end-stage renal disease patients in The Netherlands. Nephrol Dial Transplant, 18(3), 552-558. http://dx.doi.org/10.1093/ndt/18.3.552

Ting, S. M., Nair, H., Ching, I., Taheri, S., \& Dasgupta, I. (2009). Overweight, obesity and chronic kidney disease. Nephron Clin Pract, 112(3), c121-127; discussion c127.

Trevisan, M., Liu, J., Bahsas, F. B., \& Menotti, A. (1998). Syndrome X and mortality: a population-based study. Risk Factor and Life Expectancy Research Group. Am J Epidemiol, 148(10), 958-966. http://dx.doi.org/10.1093/oxfordjournals.aje.a009572

Valdes, C., Garcia-Mendoza, M., Rebollo, P., Ortega, T., \& Ortega, F. (2006). Mental health at the third month of haemodialysis as a predictor of short-term survival. Nephrol Dial Transplant, 21(11), 3223-3230. http://dx.doi.org/10.1093/ndt/gfl392

Wang, G. S., Fang, D. G., Shu, B. G., Lin, C. C., \& Shen, G. W. (2009). The Prevalence of Metabolic Syndrome in a Group of Patients Receiving Long-Term Hemodialysis in Eastern Taiwan. Acta Nephrologica, 3, 201-205.

Wolfe, R. A., Ashby, V. B., Daugirdas, J. T., Agodoa, L. Y., Jones, C. A., \& Port, F. K. (2000). Body size, dose of hemodialysis, and mortality. Am J Kidney Dis, $35(1), \quad 80-88$. http://dx.doi.org/10.1016/S0272-6386(00)70305-2

Yoo, J. S., Jeong, J. I., Park, C. G., Kang, S. W., \& Ahn, J. A. (2009). Impact of life style characteristics on prevalence risk of metabolic syndrome. $J$ Korean Acad Nurs, 39(4), 594-601. http://dx.doi.org/10.4040/jkan.2009.39.4.594

Young, D. O., Lund, R. J., Haynatzki, G., \& Dunlay, R. W. (2007). Prevalence of the metabolic syndrome in an incident dialysis population. Hemodial Int, $11(1), \quad$ 86-95. http://dx.doi.org/10.1111/j.1542-4758.2007.00158.x 